\title{
SEISMIC BEHAVIOUR OF OPEN GROUND STOREY REINFORCED CONCRETE BUILDINGS
}

\author{
Gautham. A ${ }^{1}$, K. Gopikrishna ${ }^{2}$ \\ ${ }^{1}$ M.Tech Student, NIT Warangal, gauthamanbumani@gmail.com \\ ${ }^{2}$ Assistant Professor, NIT Warangal.
}

\begin{abstract}
Open ground storey (OGS) buildings are the most common type of building configurations witnessed particularly in the urban areas due to their inherent functional advantages (Viz., basement/underground parking facilities in Apartment and Commercial complexes). These categories of buildings usually referred as soft storey buildings. These configurations have shown poor seismic performance across the world due to sudden drop in stiffness and strength in open ground storey. Several open ground storey buildings have collapsed even during Bhuj earthquake in 2001 emphasising the need to understand its seismic behaviour. This led to special considerations of specification of large design forces in IS1893 part1 for the soft storey compared to the rest of the structure. These considerations increased the shear capacity of weak storey columns to prevent collapse and subsequent loss of life. Hence, the present study is focussed on simulating the open ground storey buildings. Non-linear static analysis (Pushover) is performed using the response spectrum specified in the IS code. Further, the importance of masonry infill wall and its contribution for strengthening the open ground storey is also discussed.
\end{abstract}

****

\section{INTRODUCTION}

Reinforced concrete framed structures are most common type of building configurations witnessed particularly in urban and semi-urban areas in India. These structural configurations have non- structural masonry infill walls in between the frame structures. Further, the ground storey in most of the structures is kept free due to provision of ample parking space in high rise residential and commercial complexes, leading to soft storey structures.It has been clearly established in literature that these types of structural configurations have suffered extensive structural damage during past earthquakes throughout the world. This is mainly attributed due to sudden reduction in strength and stiffness at the open ground storey [1]. Further, the concentration of damage on the ground storey columns are attributed to the plastic hinge formation both at top and bottom of the columns. Conventionally these open ground storey structures (OGS) are analysed ordinary moment resisting frame (OMRF) without masonry infill walls. The presence of infill walls in the upper floors and ground floor being free from infill walls cause sudden drop in stiffness in the ground storey columns and subjected to large deformations and higher shear forces making them vulnerable during earthquakes. Hence, while designing these flexible ground storey columns, IS1893 (2002) part1 permits simplified analysis by enhancing the shear force and bending moments in open ground storey columns by a magnification factor of 2.5. These considerations increased the shear capacity of weak storey columns to prevent collapse and subsequent loss of life. But the real behaviour of the OGS can be captured only by modelling the stiffness of the infill walls in the upper storeys[2].

Hence the present study is focussed on studying the seismic behaviour of open ground storey building with and without consideration of infill walls using commercial software package SAP2000. Further, the contribution of the infill wall in enhancing the seismic performance level of OGS when placed strategically in ground floor is studied. It can be observed from the results that when the infill walls are placed strategically as described in model S3 without much affecting the functionality of the structure, the performance of the structure has increased significantly without collapse.

\section{DESCRIPTION OF MODEL AND ANALYSIS}

\subsection{Geometry}

The building model is as shown in the Fig. 2 having 5 bays in the $\mathrm{X}$ and $\mathrm{Y}$ directions with a bay width of $5 \mathrm{~m}$. The building is a residential building having $\mathrm{G}+5$ floors with $3 \mathrm{~m}$ storey height. Infill walls of thickness $230 \mathrm{~mm}$ are located in the outer frames in each floor except the ground floor. The plan of the building is kept symmetrical in both orthogonal directions to avoid the torsion irregularity. The building elements are modelled using SAP2000. The columns are of uniform size of $300 \mathrm{~mm} \times 600 \mathrm{~mm}$ while the dimensions of the beams are $230 \mathrm{~mm} \times 450 \mathrm{~mm}$. The response spectrum is adopted as per IS 1893 part1 for seismic zone II and soil type II. 


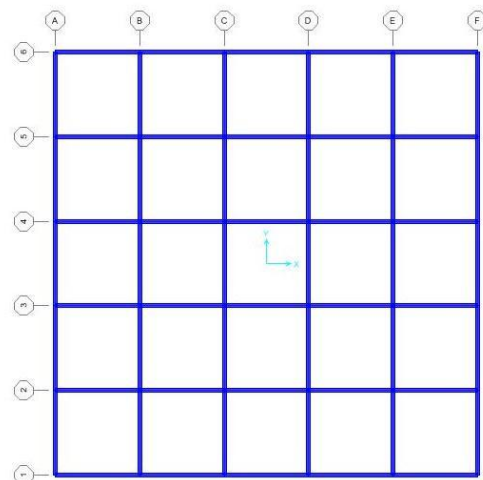

Figure.1(a): plan of the model

\subsection{Material Properties}

M30 grade of concrete and Fe415 grade of reinforcing bars are used for all the members considered under study. Unit weights of concrete and masonry are $25 \mathrm{kN} / \mathrm{m}^{2}$ and $17.65 \mathrm{kN} / \mathrm{m}^{2}$ respectively. Modulus of elasticity of masonry is taken as $3.5 \mathrm{GPa}$ with a poisons ratio of 0.17 .

\subsection{Modelling of masonry infill walls}

Stafford Smith formulated the expression for computing the width of equivalent diagonal strut for modelling infills. The parameters $\alpha \mathrm{L}$ and $\alpha \mathrm{H}$ are estimated on the basis of a beam on elastic foundation. He proposed the following equations to compute the value of $\alpha \mathrm{L}$ and $\alpha \mathrm{H}$ which depend upon the relative stiffness of the frame and the infill. [5]

$$
\begin{array}{ll}
\mathrm{W}={ }_{2}^{1} \sqrt{\propto_{h}^{2}+\propto_{L}^{2}} & \text { Equation-1 } \\
\propto_{\mathrm{h}}=\frac{\pi}{2} \sqrt[4]{\frac{4 E_{f} I_{c} h}{E_{m} t \sin 2 \theta}} & \text { Equation-2 } \\
\propto_{\mathrm{L}}=\pi \sqrt[4]{\frac{4 E_{f} I_{b} L}{E_{m} t \sin 2 \theta}} & \text { Equation-3 }
\end{array}
$$

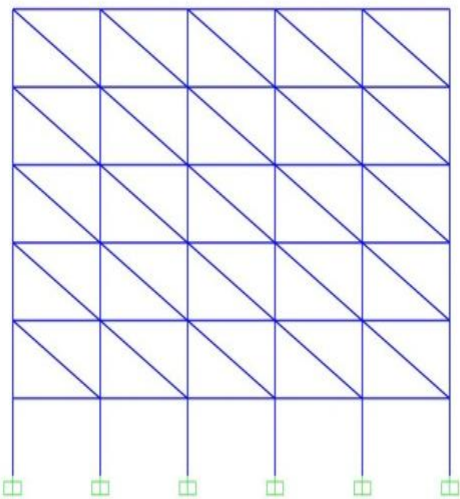

Figure.1(b): OGS model

Where $E_{m}$ is modulus of elasticity of the masonry infill, $E_{f} i s$ the elastic modulus of frame, $t$ is the thickness of the infill material, $\mathrm{h}$ and $\mathrm{L}$ are the height and length of the masonry infill respectively. $I_{b}$ and $I_{c}$ are the moments of inertia of the beam and column respectively.

\section{MODELS CONSIDERED FOR ANALYSIS}

A total of seven models are considered for analysis:

* Bare frame: - RCC frame taking the weight of infill but neglecting the effect of infill stiffness.

* OGS frame: - Effect of stiffness is considered excepting the ground storey.

* Fully infill model:-Effect of stiffness considered for each floor.

* S1:-OGS frames strengthened by the addition of $60 \%$ infill walls at ground storey.

* S2:- OGS model with $40 \%$ infill in the open storey in the interior bays.

* S3:- OGS model with $40 \%$ infill in the soft storey in the exterior bays.

* IS frame:- OGS frame with ground storey columns designed for a MF of 2.5 (increased dimensions of ground storey columns: $600 \mathrm{~mm}$ x $850 \mathrm{~mm}$ ).

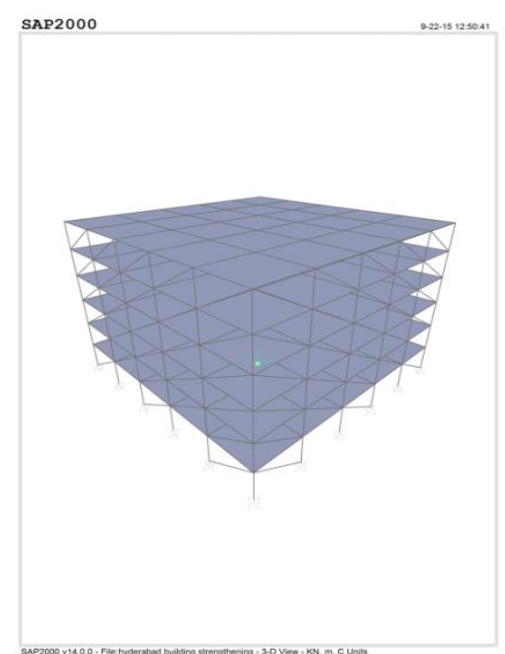




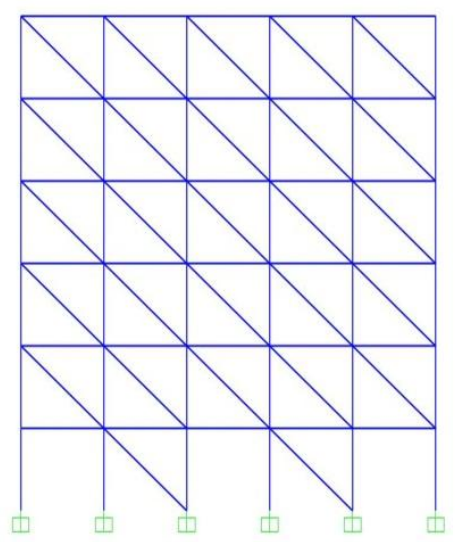

(b)

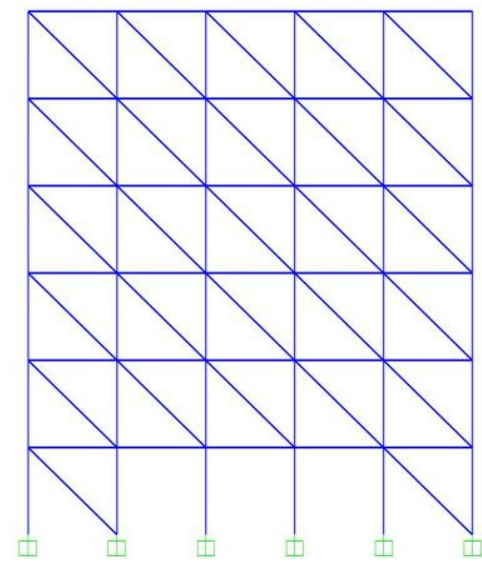

(c)

Figure.2:S1 (a); S2 (b); S3 (c)
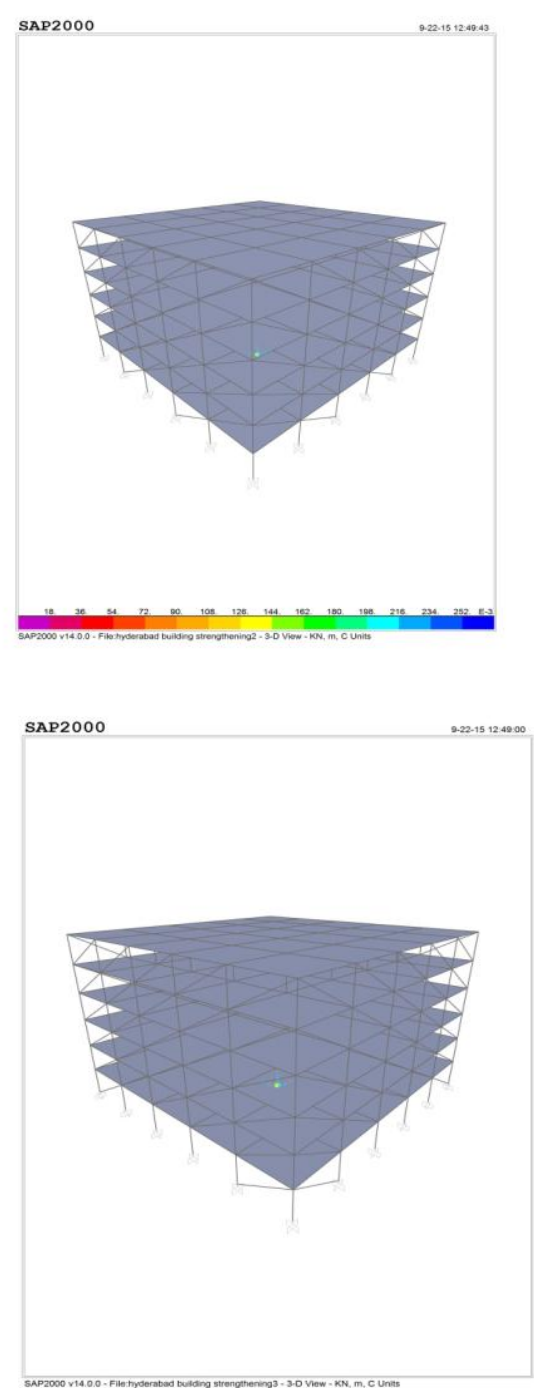

Infill walls possess large lateral stiffness and hence draw a considerable share of the lateral load.

\section{Comparison of Performance levels}

- From the push over analysis results of the OGS model, it can be seen that the ground storey columns are weak and show highest storey drift at a performance level of Life Safety (LS) based on storey drift ratios given in ATC40.

- The IS modified frame is found to improve the performance of the structure, but the ground storey columns still undergo large lateral displacements and develop plastic hinges.

- Push over analysis results of the three strategies (S1, S2 and S3) indicates their performance levels and table.1indicates the performance points and performance levels of the OGS frame, the strengthened frames S1, S2, S3, the IS modified frame and also the fully infilled frame. 

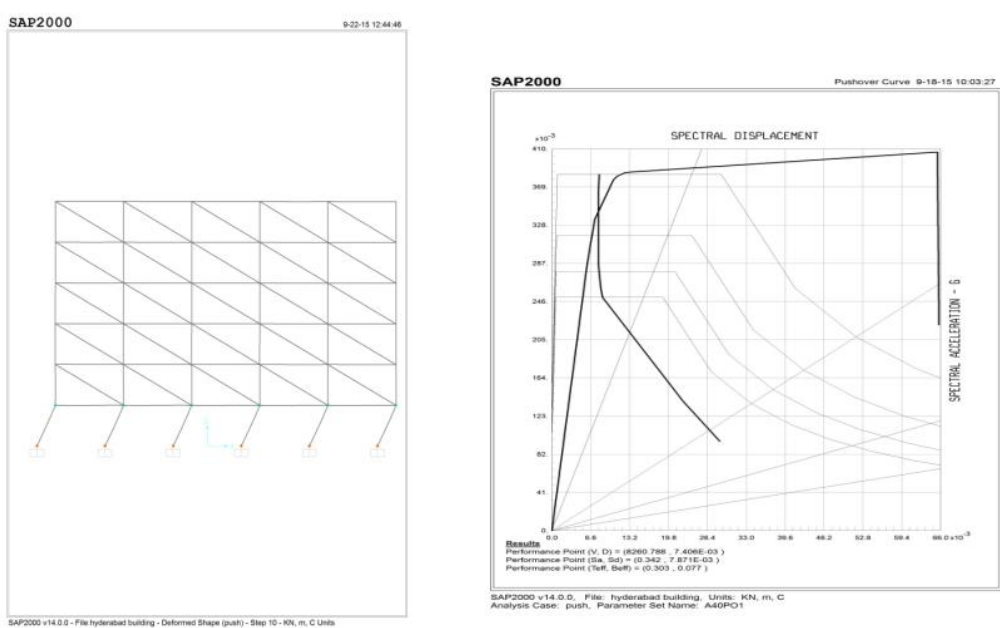

Figure.3:hinge formation in OGS frame(left) ; performance point for OGS frame(right)

\begin{tabular}{|c|c|c|}
\hline Building & Performance point $(\mathrm{kN}, \mathrm{mm})$ & Performance state \\
\hline OGS frame & $(8260,7.41)$ & Life Safety \\
\hline S1 & $(8228,0.16)$ & Immediate Occupancy \\
\hline S2 & $(7627,0.535)$ & Immediate Occupancy \\
\hline S3 & $(8630,0.24)$ & Immediate Occupancy \\
\hline Fully infill frame (FI) & $(8058,0.11)$ & Immediate Occupancy \\
\hline IS frame & $(7298.5,1.171)$ & Damage control \\
\hline
\end{tabular}

Table.1: Performance point and Performance states

- From table.1 it is clear that even though the IS frame improves the performance of the OGS model; the deformation is still high.

- The deformationsof the strengthened models are lower and offer better performance than the IS frame. Strategies S1 and S3 significantly improves the performance state of the OGS from Life Safety to Immediate Occupancy.

\section{Comparison of storey drifts}

- The plot showing the inter-storey drifts vs. storey number is developed for each model as shown in Fig.5.

- The OGS frame has large inter-storey drift in the first floor having a performance level of Collapse Prevention (CP).

- The IS modified frame though it increases the performance of the structure, still lies in the IO - LS range (Damage Control).

- The storey drift for S1 and S3 are uniform while for S2, the first storey shows higher storey drift.

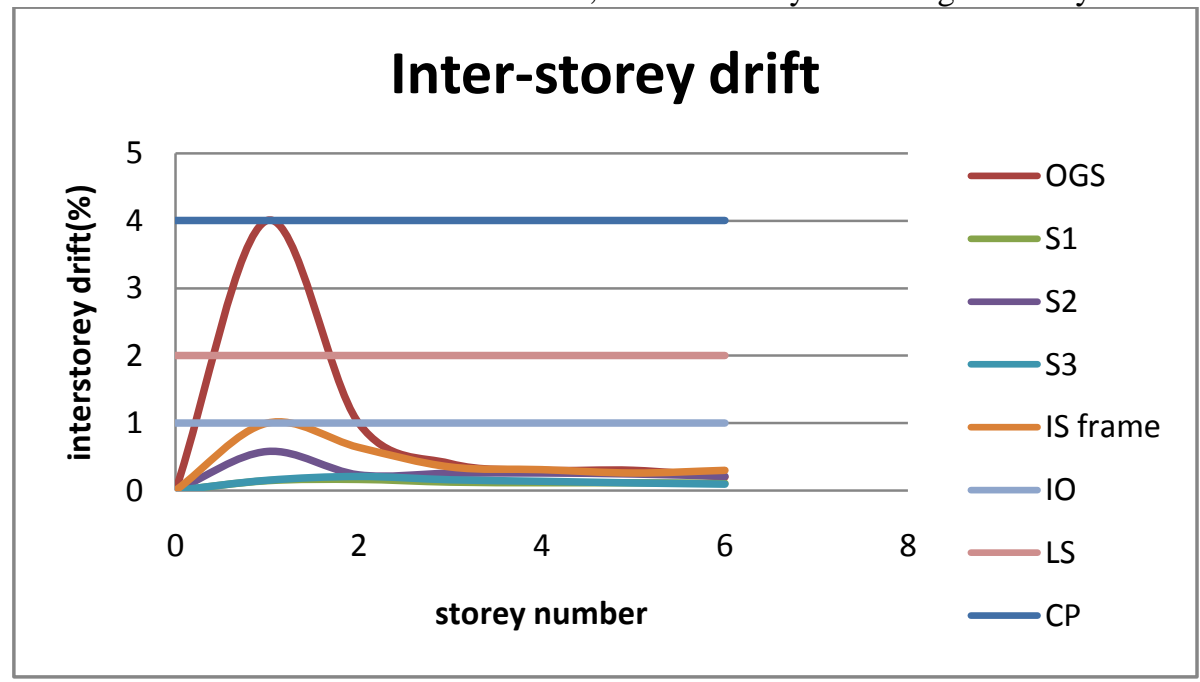

Figure.4:Inter-storey drifts 


\section{Comparison of Stiffness}

- The initial stiffness obtained from the capacity curve for fully infilled frame is the highest having a value of $8433 \mathrm{kN} / \mathrm{mm}$.

- In $\mathrm{S} 1,60 \%$ of the open area in the ground floor is filled with infill and the corresponding stiffness is $8215 \mathrm{kN} / \mathrm{mm}$ (i.e. $96 \%$ of FI) while the percentage of open area infilled in S2 and S3 are 40\% and their corresponding stiffness values are $66 \%$ and $96 \%$ respectively.

- It is evident from these results that S2 has comparable stiffness to the FI at $40 \%$ infill area while S1 takes $60 \%$ of the open area.

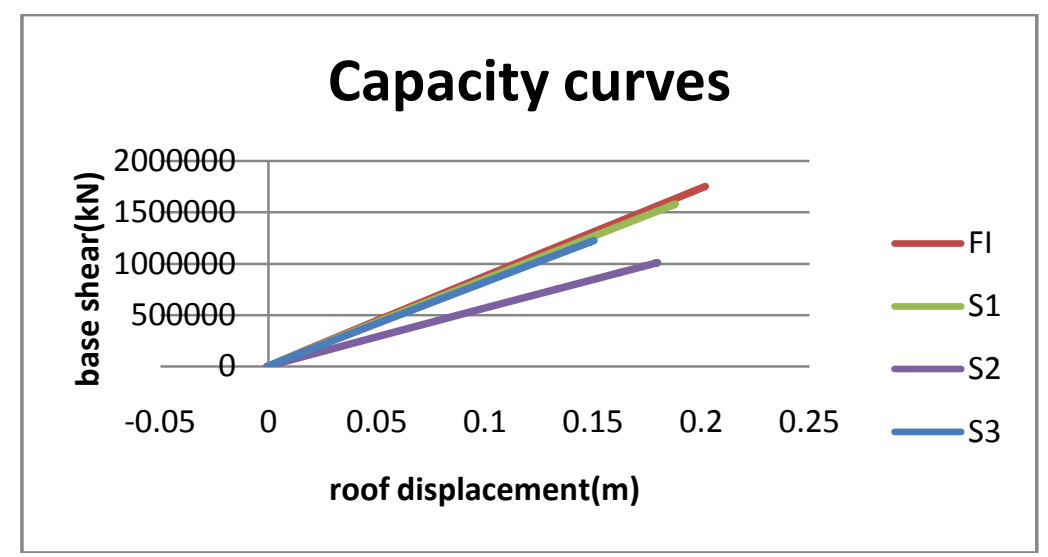

Figure.5: Building capacity curves

\section{Comparison of time period}

Figure.7shows the variation of time period of vibrationvs mode numberfor the OGS frame as well as the strengthened frames. It can be seen that the presence of infill in the structures reduces the time period of vibration of the structure.

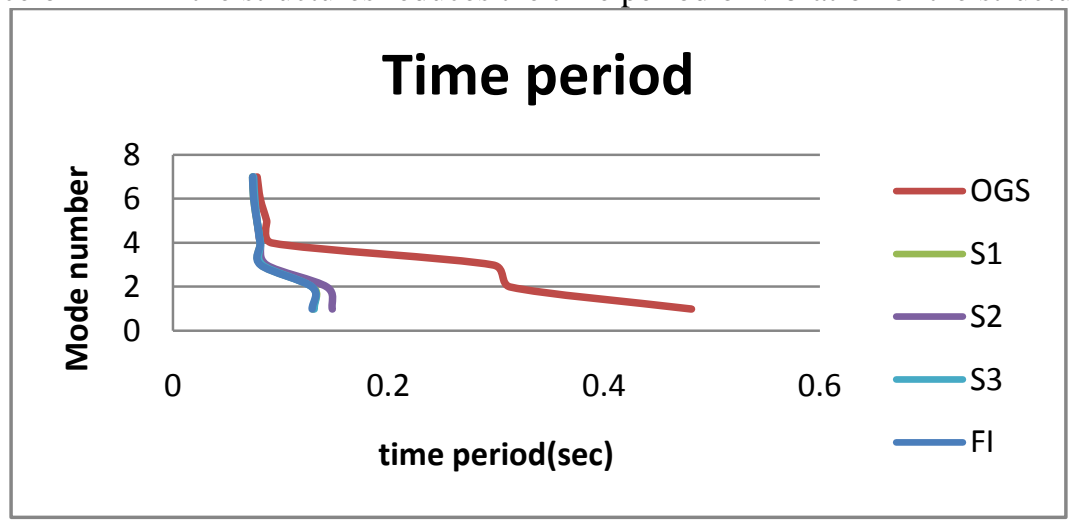

Figure.6:time period vs. mode number

\section{CONCLUSION}

This study highlights the poor seismic performance of a building with soft ground storey. Seismic analysis of models with soft storey was performed and effect of infill in improving the stiffness of the bare frame was observed. From the seismic analysis of the various models considered, the following conclusions are drawn.

* The effect of masonry infill is found to increase the lateral stiffness of the bare frame structure by a magnification factor of 7.5.

* The OGS frame is found to be at a performance state of Life Safety as per the storey drift ratios given in ATC40. Hence strengthening strategies are adopted to increase the performance state of the OGS frame.
* The modification factor of 2.5 given in IS 1893 part1 is found to improve the performance of the OGS frame but still produces large displacements in the soft storey.

* The time periods of the infilled frames are less than the OGS frame due to the increased stiffness offered by the infills.

* Out of the three strategies considered, S1 frame gave the best results in terms of capacity and performance point but occupies $60 \%$ of the open space limiting its functionality.

* Both S1 and S3improve the stiffness of the OGS frame to the level of $96 \%$ of the fully infilled frame. But S3 has less than $50 \%$ of its ground storey level restricted $(40 \%)$ thereby improving functionality as compared with S1. 


\section{NOTATIONS}

$>\alpha_{H}$ and $\alpha_{L}-$ horizontal and lateral projection of the diagonal strut

$>\theta-$ angle the diagonal strut makes with the horizontal.

$>E_{m}$ and $E_{f}-$ modulus of elasticity of masonry and frame respectively.

$>$ FI - fully infilled frame

$>\mathrm{h}$ - height of the infill wall

$>\mathrm{I}_{\mathrm{b}}$ and $\mathrm{I}_{\mathrm{c}}-$ moment of inertia of beam and frame.

$>\mathrm{L}$ - length of the infill wall

$>$ OGS - Open Ground Storey

$>\mathrm{S} 1, \mathrm{~S} 2, \mathrm{~S} 3$ - strengthening strategies 1,2 and 3.

$>\mathrm{t}$ - thickness of the masonry infill

$>\mathrm{W}$ - width of equivalent diagonal strut

\section{REFERENCES}

[1] Thusar. K. Padhy, A Meher Prasad, DevdasMenon (2010) - "Seismic Performance Assessment of Open Ground Storey Buildings" Journal Of Structural Engineering, Vol. 37, No. 2, 117-124.

[2] D.J.Chaudari,Prajakta T. Raipure, (2015) - “ Fragility Analysis of Open Ground storey RC Building designed using various multiplication factors" International
Journal of Research in Engineering and Technology, Volume 4, Issue 4, eISSN: 2319-1163

[3] L. Teresa Guevara - Perez (2012) - " Soft storey and Weak Storey in Earthquake Resistant Design: A MultiDimensional Approach" Proceedings of the 15th World Conference on Earthquake Engineering, Lisboa.

[4] C V R Murthy, Sudhir K Jain (2000) - “ Beneficial influence of masonry infill walls on seismic performance of RC Frame Buildings" Proceedings of the 12th World Conference on Earthquake Engineering, Auckland, New Zealand

[5] Vindhya Bhagawan, G.V. Sowjanya, Chethan Kumar B, Sandheep Kumar D.S (2014) - "Seismic Performance of Friction Pendulum bearing by considering Storey drift and lateral displacement" International Journal of Research in Engineering and Technology, Volume 3, Issue 8, eISSN: 2319-1163.

[6] IS 1893 Part 1 (2002) "Indian Standard Criteria for Earthquake Resistant Design of Structures", Bureau of Indian Standards, New Delhi.

[7] Applied Technical Council (1996) “ Recommended methodology for seismic evaluation and retrofitting of buildings" Report No. ATC-40, Redwood City, California. 